\title{
STUDY ON THE SPATIAL RELATIONSHIP BETWEEN LANDSCAPE RECREATION SERVICE DEMAND AND URBANIZATION - A CASE STUDY IN SHANGHAI
}

\author{
BING, Z. ${ }^{*}-$ QIU, Y. - ZHONG, W. - JIANG, H. \\ College of Hospitality Management, Shanghai Business School \\ 123 Fengpu Avenue, Fengxian District, Shanghai, China \\ (e-mail:xiaobing0707@126.com,caddy513416@126.com,jianghong007@126.com; \\ phone: +86-136-6186-0799) \\ *Corresponding author \\ e-mail:xiaobing0707@126.com \\ (Received 27 $7^{\text {th }}$ Feb 2019; accepted $3^{\text {rd }}$ May 2019)
}

\begin{abstract}
In the traditional ecosystem service evaluation, non-material services such as culture and recreation services are difficult to accurately quantify due to the lack of a powerful evaluation model. Compared with ecosystem services, landscape services emphasize all the tangible and intangible services that landscape ecosystems provide to humans in the spatial pattern. Social media photos can be used for perceived services demand evaluation on the landscape scale. The study of spatial relationship between recreation service demand (RSD) and urbanization complements the integrity of the landscape service supply and demand relationship framework. Firstly, this paper analyzes the spatial autocorrelation and seasonal differences of landscape recreation service demand through Global Moran's I. The analysis shows that there is a highly significant spatial agglomeration and certain seasonal differences in landscape recreation service demand. Secondly, the bivariate Global Moran's I is used to analyze spatial correlation between landscape recreation service demand and urbanization, The result shows that there is a positive spatial correlation between urbanization indicators and landscape recreation service demand in different seasons. Thirdly, the bivariate LISA method is used to show the spatial agglomeration relationship between landscape recreation service demand and urbanization indicators in different seasons. Finally, it is verified that the spatial lag model and the spatial error model are more suitable for measuring the dependence than the linear regression least squares (OLS). At the same time, population density (PD) has a positive impact on landscape recreation service demand in different seasons, while landscape recreation service demand in autumn is also positively affected by non-urbanization factors and negative impact of GDP, which also proves space spillover effect between landscape recreation service demand and urbanization. The above conclusions can be used as important information for urban landscape planning and decision-making.
\end{abstract}

Keywords: recreation services demand, landscape services, spatial dependence, spatial correlation, Moran's I, urbanization

\section{Introduction}

Today, human beings are considered an indispensable part of the landscape. At the same time, human beings also benefit from the functions provided by the landscape and the natural environment. Therefore, the research on ecosystem service demand is gradually starting (Burkhard et al., 2014; Schroter et al., 2015; Villamagna et al., 2013), the difficulty of data collection and the measurement limitations of time scales have relatively limited the progress of demand research. At the same time, the spatial alienation of ecosystem service demand, supply and consumption have limited the study of ecosystem service supply and demand trade-offs and spatial heterogeneity (Syrbe and Walz, 2012). 
The International Classification of Ecosystem Services (Hainesyoung et al., 2009; Hainesyoung and Potschin, 2013) identifies Cultural Ecosystem Services (CES) as a very important component. In recent years, cultural service value assessment research has developed rapidly (Bieling et al., 2014; Hermes et al., 2018; Van Berkel and Verburg, 2014). Recreational services are defined as the "recreational pleasure people derive from natural or cultivated ecosystems" (MEA, 2005; TEEB, 2010), which have a positive impact on social well-being (Hermes et al., 2018). However, non-material services such as cultural services and recreation are difficult to accurately quantify due to the lack of a powerful model for evaluation (Shaw et al., 2016; Tenerelli et al., 2016), the spatial and temporal ectopicity of service supply and demand is more pronounced (Milcu et al., 2013).

The basic spatial unit of the ecosystem service flow includes the supply unit, the connection unit and the use unit. The recreation service can be used by the beneficiary without passing through the carrier, the first assessment perspective should come from the beneficiary itself (Lie et al., 2017). Ecosystem services perceived by consumers and generating benefits can constitute effective demand (Yan et al., 2017), people's aesthetic preferences can be used as a means of recreational services demand assessment (Peña et al., 2015). The social media photos provide an opportunity to "excavate the perception, cognition or activity of many people" and reflect the relationship between landscape attributes and landscape preferences (Tieskens et al., 2018), which can be used for perceived recreation service demand evaluation on a landscape scale (Michael et al., 2018), is becoming an increasingly attractive source of cultural service assessment (Oteros-Rozas et al., 2017). The data and content analysis reflects recreation services supply on the landscape scale, while demonstrating the effective demand of people, and promotes the improvement of existing assessment methods on time scales and spatial scales (Michael et al., 2018).

Population and economic factors often affect ecosystem service demand, while land cover and land use are directly related to ecosystem service supply capacity (OterosRozas et al., 2017). Among them, there is a certain spatial correlation between the supply of ecosystem services and landscape features and urbanization (Oteros-Rozas et al., 2017; Syrbe et al., 2012; Zhang et al., 2018). In recent years, ecosystem services research has emphasized the relationship between ecosystems and human social systems at the landscape scale (Wu et al., 2013), focusing on ecosystem service needs assessments. At present, the spatial correlation between recreational service demand and landscape features has also been verified (Oteros-Rozas et al., 2017). So, is there a spatial correlation between recreational service demand and urbanization? This answer will complement the integrity of the LRS supply-demand relationship study at the landscape scale (Fig. 1).

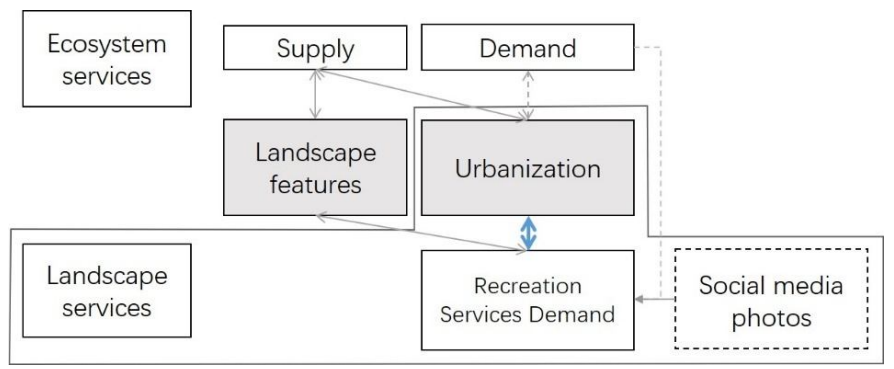

Figure 1. Conceptual framework linking ecosystem services supply and demand. The contents of block diagram are the research topics of this paper 
Is there a spatial autocorrelation of landscape recreation service demand in cities with developed tourism (Goal 1)? Is there any seasonal difference in this spatial autocorrelation (Goal 2)? Is there a spatial correlation between landscape recreation service demand and urbanization (Goal 3)? Does the demand for landscape recreation services have a spatial dependence on the level of urbanization (Goal 4)? The above questions are the research objectives of this paper. This paper aims to discuss the spatial distribution of landscape recreation service demand from the perspective of people's needs. This method can explain whether landscape recreation service supply and demand are affected by landscape features and urbanization at the same time, provide important information for landscape planning and decision making (Maes et al., 2012; Syrbe and Walz, 2012).

\section{Methodology}

\section{Study area}

The city is a region where human society and ecosystems interact closely. Landscape recreation services are an important contribution of landscape to human well-being. As a famous international tourist city, Shanghai's tourism demand has certain seasonal differences, and the off-season and peak seasons are more obvious (Table 1).

Table 1. The number and ratio tourist receptions and social media photos in different seasons

\begin{tabular}{c|c|c|c|c|c}
\hline & Spring & Summer & Autumn & Winter & Whole year \\
\hline Inbound tourists (thousand) & 2273.5 & 2011.75 & 2266.5 & 1745 & 8297.75 \\
Ratio (\%) & $27.40 \%$ & $24.25 \%$ & $27.32 \%$ & $21.03 \%$ & $100 \%$ \\
Social media photos & 855 & 741 & 838 & 522 & 2956 \\
Ratio (\%) & $28.92 \%$ & $25.07 \%$ & $28.35 \%$ & $17.66 \%$ & $100 \%$ \\
\hline
\end{tabular}

The number of inbound tourists is calculated by the average of the data from 2014 to 2017 . The data comes from the website of the Shanghai Municipal Culture and Tourism Bureau (http://lyw.sh.gov.cn/)

Therefore, this paper selects Shanghai urban area as the research scope. Shanghai's urban ecosystem is highly complex, human activities are intensive, and tourism is developed. It can be used as a typical area for studying landscape recreation service demand (Fig. 2).

\section{Data}

\section{Social media photos}

The data of social media photos used in this study belongs the Yahoo Lab Research Project (Thomee et al., 2015), which includes 100 million global photo information published on the Flickr platform from 2004 to 2014, in addition to photo elements. It includes 23 types of information such as photo number, shooting time, title, description, deep learning label, latitude and longitude. In this database, all photos of Shanghai geographic coordinates are extracted, and several types of information indicators such as photo number, shooting time, deep learning label, and latitude and longitude are selected for this study. 


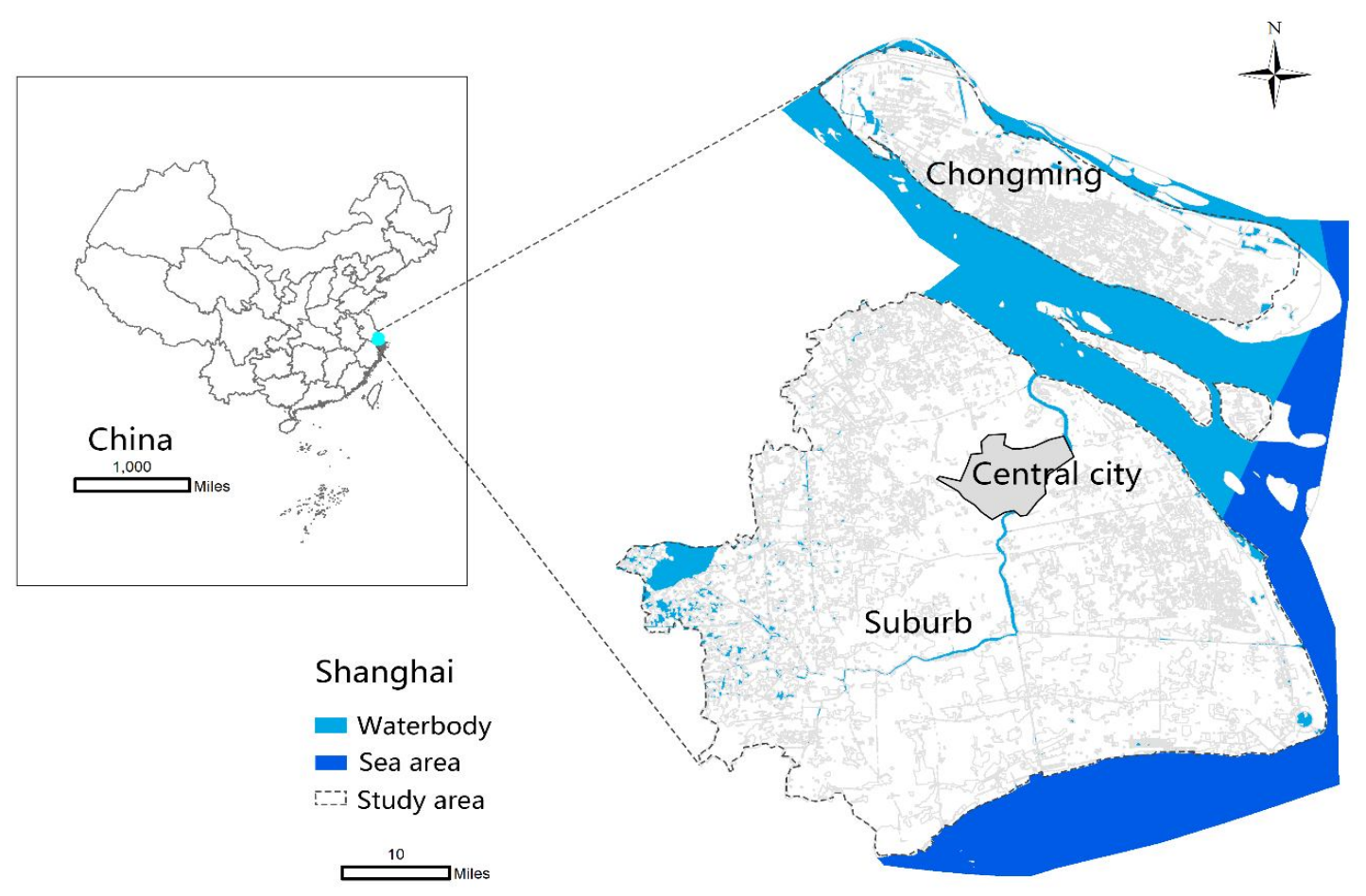

Figure 2. The dotted line in the figure is the study area

There are a total of 125,327 photos in Shanghai. First, in order not to repeatedly calculate the same tourist's perception of the same landscape, the duplicate data released at the same time is excluded. Secondly, in order to analyze the tourist's perception of the natural landscape, we remove the deep learning label as "empty". "Indoor", "outdoor", "People", "architecture", etc., which do not reflect the relationship between human activities and natural landscapes; finally, a total of 2,956 data records (Table 1) that meet the criteria are selected, according to spring (March to May), summer (June to August), autumn (September to November), winter (December to February), and the whole year. The proportion of photo data in different quarters is similar to that of inbound tourism. The proportion in spring is the highest, which is $11.26 \%$ higher than that in winter. It can be seen that the social meida photos data can be used to analyze the seasonal differences in landscape recreation demand. In this paper, the filtered data table is imported into Arcgis10.1 software and converted into projection data. The projection uses the WGS_1984_UTM_Zone_51N coordinate system.

\section{Urbanization}

Spatial distribution data of population density and GDP density in $1 \times 1 \mathrm{~km}$ resolution raster, obtained from the Resource and Environment Data Cloud Platform (http://www.data.ac.cn). The two datasets were spatialized by Interpolating statistical data to spatial grids with consideration of local land use, the nighttime light index, and other remote sensing information. The data format is gird. The author imported the data into ArcGIS10.1 software, intercepted the data according to the boundary of the study 
area, converted it into vector data, and adjusted the projected coordinate system to be consistent with the photo data.

\section{Spatial correlation analysis}

\section{Spatial autocorrelation of landscape recreation services demand}

Spatial autocorrelation is an important indicator to test whether the attribute value of an element is significantly associated with the attribute value of its adjacent space point. Global Moran's I is used to assess whether landscape recreation service demand belong to cluster distribution, discrete distribution or random distribution, $p$ value indicates the probability of occurrence of this trend, and z score is a multiple of standard deviation. Moran's I $>0$ represents spatial positive correlation, the larger the value, the more obvious the spatial correlation; Moran's I $<0$ represents the spatial negative correlation, the smaller the value, the larger the spatial difference; Moran's $I=0$, indicating a random distribution.

At the same time, Anselin Local Moran's I is used to identify spatial clusters with high or low value elements, ie, statistically significant hotspots, cold spots, and spatial outliers. This tool can effectively obtain hotspots and cold spots for landscape recreation service demand (Figueroa-Alfaro and Tang, 2016).

In this paper, Arcgis10.1 software is used for data processing to generate a square grid map of $1 \mathrm{~km} \times 1 \mathrm{~km}$ in Shanghai urban area. The square grid is superimposed with geotag photo data for spatial feature analysis of landscape recreation services demand. The Spatial Autocorrelation (Global Moran's I) tool and the clustering and outlier analysis (Anselin Local Moran's I) tool were analyzed using GeoDa1.10 software. The spatial clustering analysis in the paper defines the spatial weight based on the polygon Queen contiguity, and uses the average of all adjacent positions to evaluate the degree of correlation between the $\mathrm{X}$ variable value of a position and the value of the $\mathrm{Y}$ variable.

\section{Spatial correlation between landscape recreation service demand and urbanization}

The Bivariate Moran's I tool is used to explore the spatial clustering (positive spatial correlation) and spatial discrete (negative spatial correlation) relationships between landscape recreation service demand and urbanization. The global bivariate Moran's I is used for spatial correlation analysis between landscape recreation service demand and urbanization, and the local bivariate Moran's I can be used for visual spatial correlation analysis (Anselin and Rey, 2014). For the pseudo value obtained, the spatial correlation between RSD and urbanization is set to b0.01. Four types of local spatial autocorrelation are generated by bivariate LISA: quadrant I $(\mathrm{HH})$ represents a high RED value surrounded by high urbanization values; quadrant II (HL) represents a high RSD value surrounded by low urbanization values; quadrant III (LH) represents a low RSD value surrounded by a high urbanization value and a quadrant IV (LL) representing a low RSD value surrounded by a low urbanization value.

\section{Spatial regression analysis}

In spatial cluster analysis, if there is no spatial autocorrelation in the variable, the OLS regression model can be used for analysis. If the observed value of the variable has spatial autocorrelation, it means that the residual value is not random. This situation needs to use spatial regression analysis. However, the spatial lag model and the spatial 
error model are more suitable for regression analysis (Wang, 2009). Therefore, based on the spatial autocorrelation analysis, this paper compares the significance of OLS, SLM and SEM regression analysis results and selects the best analytical model.

\section{Results}

\section{Spatial autocorrelation of landscape recreation service demand}

The results of Global Moran's I analysis show that (Table 2), the annual RSD spatial pattern shows a highly significant spatial agglomeration, with Moran's I index of 0.5094 and $\mathrm{Z}$ score of 80.3762, which can reject null hypothesis and random distribution. Compared with different seasons, RSD has the highest concentration in spring, Moran's I index is $0.5256, \mathrm{Z}$ score is 84.0242 ; LRS demand is the lowest in autumn, Moran's I index is 0.412, $\mathrm{Z}$ score is 55.2689. In general, the spatial agglomeration patterns of RSD in different seasons have certain differences, but the differences are not significant.

Table 2. Spatial autocorrelation analysis of RSD in spring, summer, autumn, winter, and whole year. Statistically significant at 1\% level

\begin{tabular}{c|c|c|c|c}
\hline RSD & Moran's I index & Expected index & Variance & Z score \\
\hline Whole year & 0.5094 & -0.0002 & 0.0063 & 80.3762 \\
Winter & 0.4748 & -0.0002 & 0.0055 & 86.5094 \\
Autumn & 0.412 & -0.0002 & 0.0074 & 55.2689 \\
Summer & 0.4397 & -0.0002 & 0.0059 & 74.7128 \\
Spring & 0.5256 & -0.0002 & 0.0063 & 84.0242 \\
\hline
\end{tabular}

The results of Local Moran's I show different types of RSD spatial aggregating patterns. It can be seen from the annual RSD spatial agglomeration feature that the $\mathrm{HH}$ area is mainly concentrated in the central area of Shanghai, and this feature has similar performance in different seasons. The HL area distribution is relatively discrete. The LH area is distributed in the southwest and south of the study area, and the spatial aggregation of RSD is most similar in autumn and whole year. The LL area is mainly distributed in Chongming Island and suburban areas in the north; the number of RSD cold spots in spring and summer is large, distributed in the marginal areas of Chongming Island and suburban areas, while the number of cold spots in autumn and winter is small. It can be seen that the regional spatial agglomeration of high RSD is strong, and the seasonal difference is relatively low; the area of low RSD has spatial agglomeration and seasonal differences (Fig. 3).

\section{Correlation analysis between landscape recreation service demand and urbanization}

This paper uses Bivariate Moran's I to test the spatial correlation between RSD and urbanization. The level of urbanization is represented by two indicators: population density (PD) and GDP. Figure 4 shows a significant positive correlation between RSD and PD. There is also a positive correlation between RSD and GDP, but the correlation is weak, and the correlation is between 0.084 and 0.118 . It can be seen that the 
correlation between urbanization and RSD is relatively stable, and the seasonal difference is not large (Fig. 4).
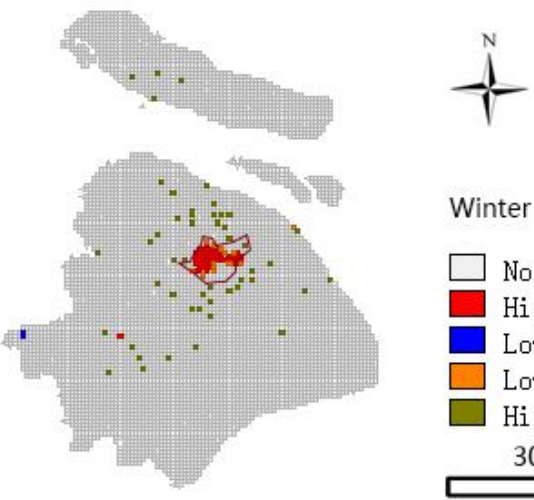

Winter
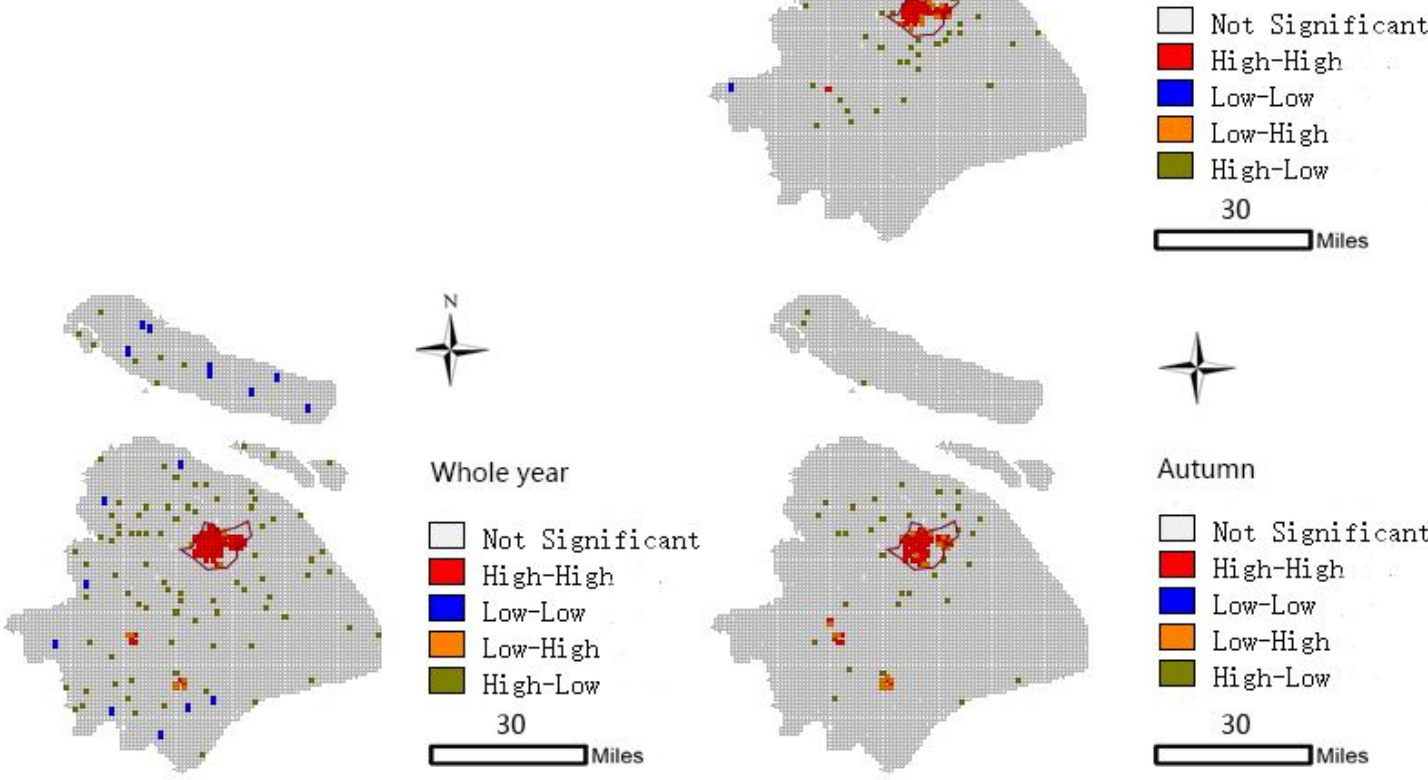

Autumn

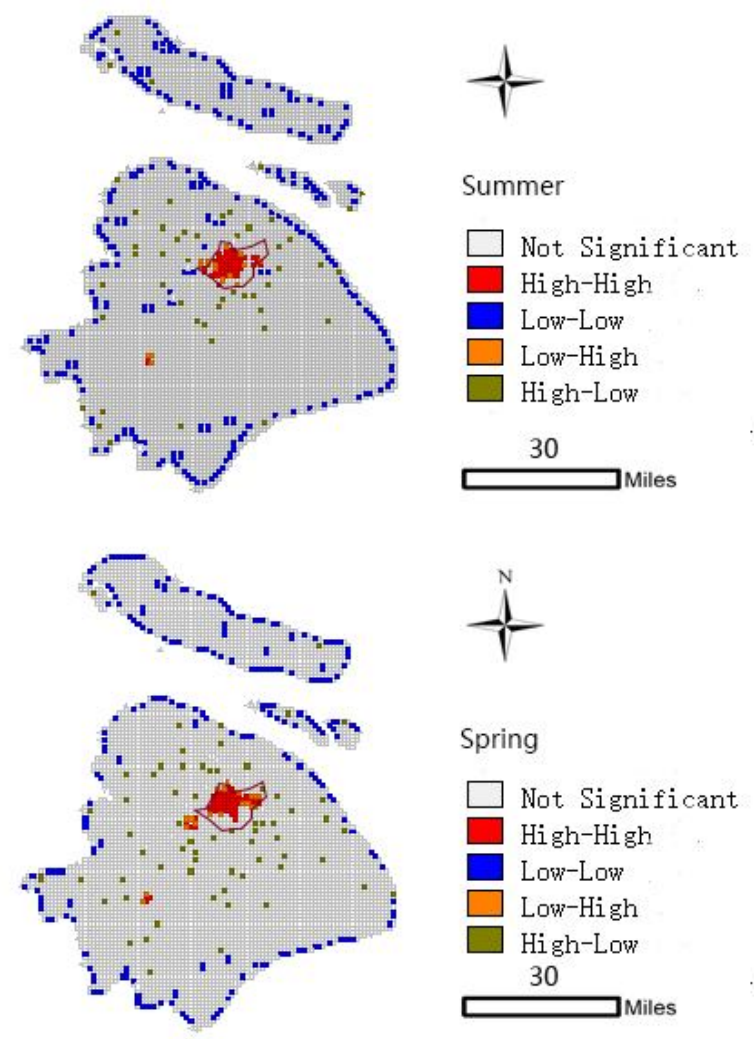

Figure 3. LISA cluster map of local Moran's I. Statistically significant at 1\% level 

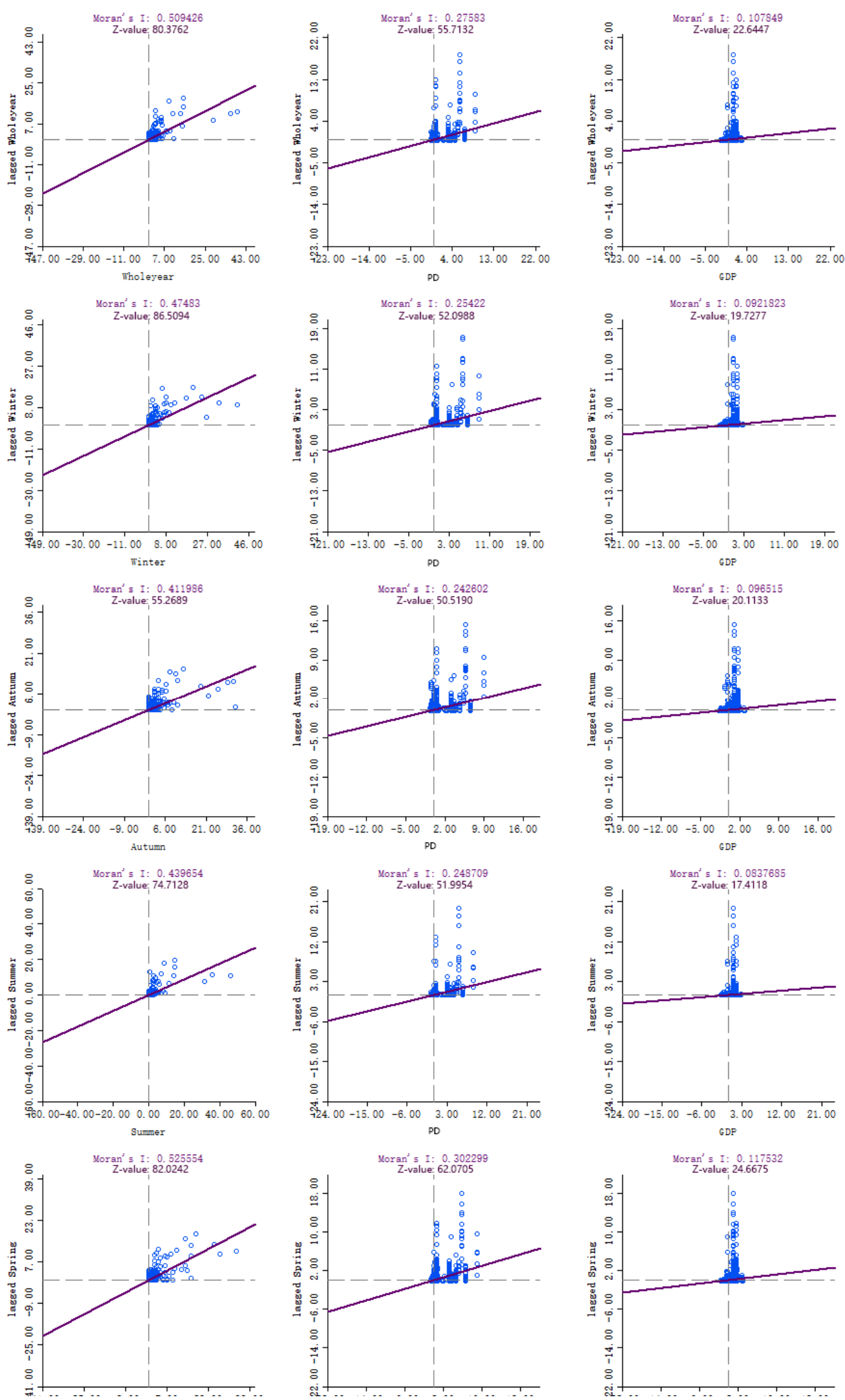

Figure 4. Bivariate Moran's I between RSD and urbanization (PD \& GDP). Statistically significant at $1 \%$ level 
The BiLISA Cluster map (Fig. 5) shows the spatial agglomeration of RSD and urbanization in different seasons. The HH area of urbanization and RSD is still mainly concentrated in the central city, with a high degree of concentration. The seasonal distribution of GDP and RSD is not much different; the high values of PD and RSD are the largest in spring. HL has the widest distribution range, PD has a high value distribution in the middle and northeast of the study area, and RSD has a low value distribution, GDP has a high value distribution in the middle and northwest of the study area, while RSD has a low value distribution. The LH region is dispersedly distributed in the southwestern part of the study area. The spatial agglomeration of urbanization and RSD is more obvious in autumn and the whole year. The LL value distribution area presents a certain space and seasonal agglomeration, mainly concentrated in the urban fringe area of spring and summer and the edge area of Chongming Island. We can get several conclusions: First, compared with the spatial distribution of urbanization, the RSD high-value space is more concentrated, mainly concentrated in the central city; second, in the low-value area of urbanization indicators, RSD appears a large range of high values in autumn. At the same time, in the low-value areas of urbanization, the low $\mathrm{RSD}$ is mainly in the urban fringe of spring and summer.

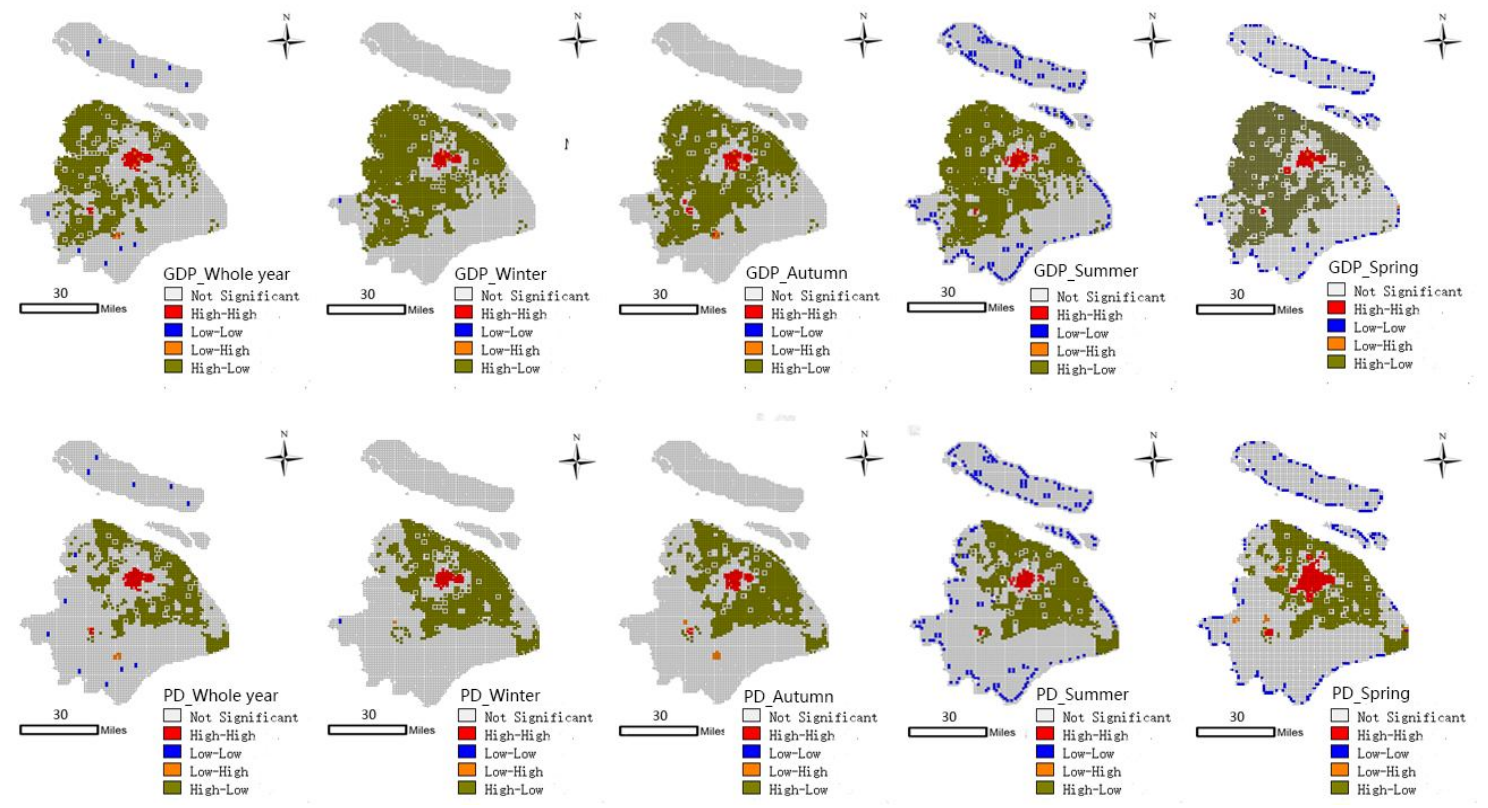

Figure 5. BiLISA Cluster map between RSD and urbanization (PD \& GDP). Statistically significant at $1 \%$ level

\section{Spatial dependence analysis of landscape recreation service demand on urbanization}

The previous analysis has obtained that the observation value of RSD is related to the geographical location, then the residuals are no longer independent of each other, and there is a certain spatial positive correlation between RSD and urbanization. Therefore, when further analyzing the causal relationship between urbanization indicators and RSD, the OLS model is no longer applicable. In this paper, the urbanized PD and GDP indicators are used as independent variables, and the RSD of different seasons is used as the dependent variable. The maximum likelihood estimation method (SLM \& SEM) is 
used for spatial regression analysis, and the OLS model results are used for comparison test (Table 3).

The OLS results show that the simulation fit is not ideal and the adjusted $\mathrm{R}^{2}$ value is relatively low. Among them, the regression fit of PD with RSD in different seasons is highly significant, while the GDP index only fits significantly with the regression of RSD in autumn and whole year. At the same time, LM tests show that LM (Lag) and LM (Error) are significant for regression analysis of RSD in different seasons, and this indicates that SLM and SEM are more suitable than OLS.

Spatial regression analysis shows that SRM is superior to OLS because Log Likelihood values increase and AIC and SC values decrease (Tables 3 and 4). SLM has the best results in RSD regression analysis in spring, summer, winter and whole year. The lag coefficient (W_LRS) in SLM is positive under pb0.001 significant condition, indicating that the RSD of four time dimensions is adjacent. The SEM has the best positive results in autumn, and the error coefficient (LAMBDA) is also positive under the pb 0.001 significance condition in the SEM, indicating that the RSD is also positively affected by non-urbanization factors in autumn.

Table 3. The results of OLS model between RSD and urbanization

\begin{tabular}{c|c|c|c|c|c}
\hline Variables & Whole year & Spring & Summer & Autumn & Winter \\
\hline Constant & -0.164 & $-0.009 * *$ & -0.003 & $-0.008^{* *}$ & $-0.005^{*}$ \\
GDP & $-13.67 * *$ & 9.015 & 0.446 & $-3.126 * *$ & 5.452 \\
PD & $0.0002 * * *$ & $16.482^{* * *}$ & $10.98^{* * *}$ & $9.36 * * *$ & $5.42 * * *$ \\
Adjusted $\mathrm{R}^{2}$ & 0.08 & 0.09 & 0.061 & 0.058 & 0.048 \\
Log likelihood & -17043.4 & 3362.47 & 3841.11 & 3836.18 & 5341.67 \\
Akaike info criterion & 34092.8 & -6718.93 & -7676.23 & -7666.37 & -10677.3 \\
Schwarz criterion & 34112.9 & -6698.76 & -7656.06 & -7646.2 & -10657.2 \\
Lagrange multiplier (lag) & $4844.73 * * *$ & $151.16^{* * *}$ & $403.02 * * *$ & $463.44 * * *$ & $128.92 * * *$ \\
Robust LM (lag) & $45.25 * * *$ & $24.65 * * *$ & $4.01 *$ & $125.86 * * *$ & $27.28 * * *$ \\
Lagrange multiplier (error) & $4824.96 * * *$ & $134.98^{* * *}$ & $399.65 * * *$ & $408.90^{* * * *}$ & $116.58 * * *$ \\
Robust LM (error) & $25.49 * * *$ & $8.46^{* *}$ & $0.64 *$ & $71.32 * * *$ & $14.94 * * *$ \\
\hline
\end{tabular}

*Statistically significant at $5 \%$ level. ${ }^{*}$ Statistically significant at $1 \%$ level. $* * *$ Statistically significant at $0.1 \%$ level

All PD coefficients are significant positive values, indicating that PD growth drives RSD growth. In the order of decreasing absolute values of PD coefficients, as the PD increases, the RSD in spring increases the most, while the demand for RSD in winter increases the least.

GDP coefficients are only significant negative values in the autumn, indicating that the RSD in the autumn has a degrading effect with the increase of GDP. At the same time, compared with the OLS model analysis, the absolute value of GDP coefficients in the SEM regression analysis of RSD in autumn is higher, indicating that the effect of spatial autocorrelation is that the negative impact of GDP increase on RSD in autumn is reduced. 
Table 4. Results of spatial regression between RSD and urbanization, only the most suitable models are shown

\begin{tabular}{c|c|c|c|c|c}
\hline & Whole year $^{\mathbf{a}}$ & Spring $^{\mathbf{a}}$ & Summer $^{\mathbf{a}}$ & Autumn $^{\mathbf{b}}$ & Winter $^{\mathbf{a}}$ \\
\hline W_LRS & $0.792 * * *$ & $0.245^{* * *}$ & $0.34 * * *$ & & $0.22^{* * *}$ \\
LAMBDA & & - & - & $0.378^{* * *}$ & \\
Constant & -0.044 & $-0.007^{*}$ & -0.002 & -0.006 & -0.004 \\
GDP & -27.74 & 4.48 & -4.00 & $-2.09^{* *}$ & 2.51 \\
PD & $10.42 * * *$ & $11.24 * * *$ & $5.79 * * *$ & $4.94 * * *$ & $2.99 * * *$ \\
Log likelihood & -15505.1 & 3426.36 & 3988.16 & 3999.89 & 5394.12 \\
Akaike info criterion & 31018.2 & -6844.71 & -7968.31 & -7993.78 & -10780.2 \\
Schwarz criterion & 31045.1 & -6817.82 & -7941.42 & -7973.61 & -10753.3 \\
\hline
\end{tabular}

${ }^{\text {a}}$ Spatial lag model

${ }^{\mathrm{b}}$ Spatial error model

W_LRS denotes spatial lag term of individual ecosystem service equation. This parameter only makes sense in spatial lag models, namely in LRS in whole year regressions. LAMBDA denotes spatial error term of individual ecosystem service equation. This parameter only makes sense in spatial lag models, namely in regressions

*Statistically significant at $5 \%$ level. $* *$ Statistically significant at $1 \%$ level. $* * *$ Statistically significant at $0.1 \%$ level

\section{Discussion}

\section{Spatial autocorrelation and seasonal differences in landscape recreation service demand}

There are certain seasonal differences in the number of tourists in the city, and this conclusion has been verified in related research on tourism activities. This paper explores the RSD spatial agglomeration model and seasonal differences through Global Moran's I and local Moran's I. The results show that the RSD in different seasons shows a highly significant spatial autocorrelation. Among them, the $\mathrm{HH}$ region is concentrated in the central city, and the seasonal difference is low; the LH region shows a certain concentration outside the central city, and the RSD in autumn is the most concentrated obviously. As an international tourist city, the hotspots of RSD in Shanghai are concentrated and stable, and are almost unaffected by the seasons. In September, "Shanghai Tourism Festival" and other events have an impact on RSD and form some new hotspots in the spatial distribution. Although it has not formed a role in other seasons, it has a significant impact on the spatial distribution of RSD throughout the year.

\section{Study on the relationship between supply and demand of recreation services}

As mentioned above, the alienation of the demand, supply and consumption of ecosystem services has limited research on supply and demand. This problem is more prominent in non-material services such as recreational services.

On the basis of the verification of the spatial supply of ecosystem services and the spatial characteristics of landscape and urbanization, the spatial correlation between RSD and landscape features is also explained by relevant research results from the perspective of consumer demand. In this paper, there is a significant positive correlation 
between RSD and urbanization, and it is not affected by seasonal differences, indicating that the spatial relationship is relatively stable. This stable spatial correlation conclusion will complement the research framework for the relationship between supply and demand of recreational services (Fig. 1). We can understand that the supply and demand capacity of recreation services is spatially related to landscape characteristics and urbanization, and can be used for supply and demand relationship models. At the same time, photo data based on geographic coordinates provides a data source for the research of recreational service demand in landscape scale and time dimension (Michael et al., 2018). The deep learning of photo content can help to analyze the specific demand of people and promote spatial heterogeneity research.

\section{Enlightenment of spatial dependence analysis on urban landscape planning}

The SLM model performed optimally in RSD regression analysis in spring, summer, winter, and year-round, and was positively affected by adjacent values (Table 4), indicating that RSD was affected by both PD and adjacent values. Therefore, it is necessary to pay attention to the protection and planning of natural landscapes in densely populated areas. Natural landscape is an important part of maintaining the sustainable development of urban ecosystems. It not only protects the natural landscape of RSD hotspots, but also drives demand growth around hotspots.

As the tourist season in Shanghai in the autumn, the distribution of high-value points of RSD also shows a certain concentration. At the same time, the SEM model is optimal for RSD regression analysis in autumn. The RSD in autumn is affected by the positive influence of PD and the negative impact of GDP, and the RSD in autumn is also positively affected by non-urbanization factors (Table 4). The research and management of RSD supply and demand in autumn needs to be comprehensively considered and evaluated, and as far as possible to plan the development of areas with high population density, while avoiding the economic business center area. It is particularly important to note that the RSD cold spots area (urban fringe area and Chongming Island fringe area) in spring and summer can be the focus of landscape planning to promote the balanced development of supply and demand.

\section{Conclusion}

This paper improves the supply and demand research framework of landscape recreation services through the study of spatial relationship between RSD and urbanization.

The spatial autocorrelation of RSD is the first research goal of this paper. Global Moran's I analysis shows that RSD has a highly spatial agglomeration. The hotspots are highly concentrated in the central area of the city, and the cold spots are relatively discrete. There are some differences in the RSD spatial agglomeration patterns in different seasons, and the distribution of cold spots in spring and summer is discrete.

The spatial correlation between RSD and urbanization is the second research goal. Bivariate Global Moran's I verifies that there is a positive spatial correlation between urbanization and RSD in different seasons.

The spatial dependence of RSD on urbanization is also a research goal. In order to avoid the influence of spatial autocorrelation, this paper uses the maximum likelihood estimation method (SLM \& SEM) for spatial regression analysis, and compares the OLS model results. The LM test showed that LM (Lag) and LM (Error) were significant 
for RSD regression analysis in different seasons, and this indicates that SLM and SEM are more suitable than OLS. The results show that the regression fit of PD with RSD in different seasons is highly significant, while GDP only fits significantly to the regression between RSD in autumn. SLM has the best results in RSD regression analysis in spring, summer, winter and whole year, indicating that RSD is positively affected by PD and adjacent values; SEM is optimal in RSD regression analysis in autumn, and RSD in autumn is positively affected by PD and non-urbanization factors, while being negatively affected by GDP, also proves the spatial spillover effect between RSD and urbanization.

Acknowledgements. The completion of this paper is funded by the project of China National Natural Science Foundation "Landscape Services spatial heterogeneity assessment and supply forecasting simulation-A Case Study of Chongming Dongtan Wetland Bird Nature Reserve in Shanghai" (41701633)

\section{REFERENCES}

[1] Anselin, L., Rey, S. J. (2014): Modern Spatial Econometrics in Practice: A Guide to GeoDa. - GeoDa Press LLC, GeoDaSpace and PySAL, Chicago, IL.

[2] Bieling, C., Plieninger, T., Pirker, H., Vogl, C. R. (2014): Linkages between landscapes and human well-being: an empirical exploration with short interviews. - Ecological Economics 105(5): 19-30.

[3] Burkhard, B., Kroll, F., Nedkov, S., Müller, F. (2012): Mapping ecosystem service supply, demand and budgets. - Ecological Indicators 21: 17-29.

[4] Figueroa-Alfaro, R. W., Tang, Z. (2016): Evaluating the aesthetic value of cultural ecosystem services by mapping geo-tagged photographs from social media data on Panoramio and Flickr. - Journal of Environmental Planning and Management. https://doi.org/10.1080/09640568.2016.1151772.

[5] Hainesyoung, R. et al. (2009): Towards a common international classification of ecosystem services (CICES)) for integrated environmental common international classification of ecosystem services (CICES)) for integrated environmental and economic accounting. - Interspeech, Conference of the International Speech Communication Association, Makuhari, Chiba, Japan, September.

[6] Hainesyoung, R., Potschin, M. (2013): Common International Classification of Ecosystem services (CICES). - Report to the European Environment Agency. www.cices.eu.

[7] Hermes, J., Berkel, D. V., Burkhard, B., Plieninger, T., Fagerholm, N., Haaren, C. V. et al. (2018): Assessment and valuation of recreational ecosystem services of landscapes. Ecosystem Services 31: 289-295.

[8] Liu, H. M., Liu, L. Y., Ding, S. Y. (2017): The impact of human activities on ecosystem services flow. - Acta Ecologica Sinica 37(10): 3232-3242 (in Chinese).

[9] Maes, J., Paracchini, M. L., Zulian, G., Dunbar, M. B., Alkemade, R. (2012): Synergies and trade-offs between ecosystem service supply, biodiversity, and habitat conservation status in Europe. - Biological Conservation 155(4): 1-12.

[10] MEA (2005): Ecosystems and Human Well-Being: Synthesis of the Millennium Ecosystem Assessment. - Island Press, Washington DC.

[11] Michael, S., Andrea, G., Sheela, A. M. (2018): A crowdsourced valuation of recreational ecosystem services using social media data: an application to a tropical wetland in India. - Science of the Total Environment 642: 356-365. 
[12] Milcu, A. J., Hanspach, J., Abson, D., Fischer, J. (2013): Cultural ecosystem services: a literature review and prospects for future research. - Ecology and Society 18(3): 261-272.

[13] Oteros-Rozas, E., Martín-López, Berta, Fagerholm, N., Bieling, C., Plieninger, T. (2017): Using social media photos to explore the relation between cultural ecosystem services and landscape features across five european sites. - Ecological Indicators 94(2): 74-86.

[14] Peña, L., Casado-Arzuaga, I., Onaindia, M. (2015): Mapping recreation supply and demand using an ecological and a social evaluation approach. - Ecosystem Services 13: 108-118.

[15] Schroter, M., Barton, D. N., Remme, R. P., Hein, L. G. (2014): Accounting for capacity and flow of ecosystem services: a conceptual model and a case study for Telemark, Norway. - Ecological Indicators 36(1): 539-551.

[16] Shaw, E., Kumar, V., Lange, E., Lerner, D. N. (2016): Exploring the utility of Bayesian networks for modelling cultural ecosystem services: a canoeing case study. - Science of the Total Environment 540: 71-78.

[17] Syrbe, R. U., Walz, U. (2012): Spatial indicators for the assessment of ecosystem services: providing, benefiting and connecting areas and landscape metrics. - Ecological Indicators 21: 0-88.

[18] TEEB (2010): The Economics of Ecosystems and Biodiversity: Ecological and Economic Foundations. Edited by Pushpam Kumar. - Earthscan, London and Washington.

[19] Tenerelli, P., Demšar, U., Luque, S. (2016): Crowdsourcing indicators for cultural ecosystem services: a geographically weighted approach for mountain landscapes. Ecological Indicators 64: 237-248.

[20] Thomee, B., Shamma, D. A., Friedland, G., Elizalde, B., Ni, K., Poland, D. et al. (2015): Yfcc100m: the new data in multimedia research. - Communications of the ACM 59(2): 64-73.

[21] Tieskens, K. F., Zanten, B. T. V., Schulp, C. J. E., Verburg, P. H. (2018): Aesthetic appreciation of the cultural landscape through social media: an analysis of revealed preference in the dutch river landscape - Landscape \& Urban Planning177: 128-137.

[22] Van Berkel, D. B., Verburg, P. H. (2014): Spatial quantification and valuation of cultural ecosystem services in an agricultural landscape. - Ecological Indicators37: 163-174.

[23] Villamagna, A. M. et al. (2013): Capacity, pressure, demand, and flow: A conceptual framework for analyzing ecosystem service provision and delivery. - Ecological Complexity 15(5): 114-121.

[24] Wang, F. H. (2009): Quantitative Method and Application Based on GIS. - Commercial Press, Beijing.

[25] Wu, J., Feng, Z., Gao, Y., Peng, J. (2013): Hotspot and relationship identification in multiple landscape services: a case study on an area with intensive human activities. Ecological Indicators 29: 529-537.

[26] Yan, Y., Zhu, J. Y., Wu, G., Zhan, Y. J. (2017): Review and prospective applications of demand supply and consumption of ecosystem services. - Acta Ecologica Sinica 37(8): 2489-2496 (in Chinese).

[27] Yao, J., He, X. Y., Chen, W. (2018): The latest process in ecosystem service flow research methods. - Chinese Journal of Applied Ecology 29(1): 335-342 (in Chinese).

[28] Zhang, Y., et al. (2018): On the spatial relationship between ecosystem services and urbanization: a case study in Wuhan, China. - Science of the Total Environment 637-638: 780-790. 